\title{
15. Coping with the implementation challenge: decision-making strategies and their implications for collaborative governance
}

Lihi Lahat and Neta Sher-Hadar ${ }^{1}$

\section{INTRODUCTION}

From the beginning of the millennium, governments have changed the way they work. In many respects the perception of a hierarchal organization that supplies services to the public is no longer the only modus operandi. Increasingly, the practice one encounters today is based on networks and collaborations with different actors from various sectors (Ansell 2012; Bevir 2012; Rhodes 2012; Sørensen and Torfing 2016b; Kekez, Howlett, and Ramesh, Chapter 1 in this volume). In part, this change is the outcome of four decades of reforms in public organizations that created a new environment for government activity. This new environment is reflected in a decline in trust in government and a decrease in the capabilities of public organizations to supply public services, resulting in the need to find new ways of operating. At the root of these new directions lies the need to reinforce the legitimacy of government and improve the capabilities of public organizations. One of the main ways to do so is by implementing collaborative mechanisms. And indeed, collaboration arrangements are one of the central features of the post-New Public Management reforms.

From the individual perspective, there is a growing need to strengthen the judgments of policymakers about when and how to utilize collaborative arrangements in general and in the service-delivery process in particular. Due to their costs and the involvement of different actors, the success or failure of these complex arrangements can have a critical impact on the policymakers' public support.

This chapter explores the benefits of these arrangements for promoting public values. While the literature deals mainly with the question of how to 
implement collaborative arrangements or how to use them in better ways, we are interested in an earlier stage. Therefore, we focus on the conditions under which it is beneficial to embrace collaborative initiatives. The chapter includes four sections. First, we describe the context that led to the rise of collaborative governance arrangements and define the term. Second, we introduce our theoretical perspective, which is based on that of Thompson and Tuden (1959), and provide examples of different kinds of collaborations from the Israeli experience. Third, we explore the connection between the typology and the six different kinds of collaboration-co-production, co-management, consultations, collaborative contracting, commissioning and certification-explored in this volume. Finally, we discuss practical implications and directions for future research.

\section{A CRISIS OF GOVERNABILITY OR A CHANGE IN SCENERY?}

Researchers have identified three waves of public administration reforms. The first, which began at the end of the nineteenth century and lasted until the end of the 1970s, was based mostly on the Weberian model and involved the desire of the modern state to exercise control via hierarchal structures. These models were based on differentiations in work functions, expertise and rational rules. The second wave from the 1980s until the end of the 1990s included the New Public Management reforms that, among other things, embraced managerial methods from the private sector, the goal that people should get value for their money, privatization, outsourcing, performance management and viewing the public as clients. The third wave from the beginning of the millennium until today, which some researchers call Post-New Public Management, contains diverse models that despite their varieties include several common features such as changing the view of serving the public from serving clients to serving citizens, emphasizing trust as a basic milestone in the activities of public organizations, collaboration with diverse actors, exploring and promoting public values, embracing holism and integrating government units as a way to cope with the fragmentation that was created in the previous wave of reform (Dunleavy et al. 2006; Pollitt and Bouckaert 2011; Stoker 2006; Van de Walle et al. 2016; Vigoda-Gadot 2009).

These trends parallel the public policy literature that emphasizes the term 'governance' instead of government. These perspectives underscore the idea that policy is a product of dialog and interaction between different actors from different sectors, and government agencies are only one of the actors in these processes (Osborne 2010; Rhodes 2012; Richards and Smith 2002). For example, Hajer (2003) uses the term 'institutional void' to describe the undermining of state institutions and the deterioration of knowledge and 
professionalism along with the strengthening of processes such as globalization and individualization. In a similar manner, Rhodes (1994) uses the term 'hollow state' to describe the pressures that state institutions experience from globalization as well as local forces. Researchers also refer to the importance of determining narratives for the formation of public policies and for the ability to identify mutual targets and values that can steer networks by using soft power mechanisms (Rhodes 2007 and Nye 2005 in Baker and Stoker 2013; Rhodes 2012; Stone in van Ostaijen and Jhagroe 2015).

The changing nature of the policy process has led to the use of less coercive tools (DeLeon 2006; Howlett 2014; Salamon 2002). Thus, we must find the proper tools or institutional arrangements that can enable dialogs among the various actors in the networks rather than relying on market or hierarchal structures (Bevir 2012; Rhodes 2012). This background is in many ways the basis for the emerging interest in collaborative governance.

\section{The Meaning of Collaborative Governance}

In the introductory chapter of this volume Kekez, Howlett, and Ramesh refer to six different collaborative service delivery arrangements. The range of collaboration features can be divided by the number and/or the centrality of the different sectors in the collaboration. The result is a continuum from 'consultation,' which still regards the public sector as the leading actor while involving civil society participants in the consultation process, to 'certification,' which includes the involvement of all three sectors but does not see the public sector as the leading actor (Cashore 2002; Cutler, Haufler, and Porter 1999; Gulbrandsen 2014; Kekez, Howlett, and Ramesh, Chapter 1 in this volume).

Our perspective on collaboration is from the government's point of view. Therefore, we question when it is worthwhile for government to implement collaborative arrangements and when it is not. Our assumption is that the public sector should be the central actor in any collaboration. Therefore, we embrace a narrower definition of collaboration-collaborative governance (see also Ansell, Chapter 2 in this volume).

Doing so, we emphasize two important elements in the collaborative governance definition. First, we refer to collaboration as to a formal, long-term, reciprocal relationship, not just cooperation or coordination. Hence, the act of collaboration involves high expectations for the greater involvement of and contribution from the different actors (Emerson and Gerlak 2014; Keast and Mandell 2014; O'Flynn 2008). Second, scholars suggest different points in time for the rise of the concept as well as different definitions of it (Ansell and Gash 2008; Emerson and Gerlak 2014; McGuire 2006; Vigoda-Gadot 2004; Wanna 2008). Some of the definitions are more wide-ranging, while others are narrower. We embrace Ansell and Gash's (2008) definition of collaborative 
governance as: "A governing arrangement where one or more public agencies directly engage non-state stakeholders in a collective decision-making process that is formal, consensus-oriented, and deliberative and that aims to make or implement public policy or manage program or assets" (Ansell and Gash 2008: 544).

\section{COLLABORATIVE GOVERNANCE IN DIFFERENT SITUATIONS: A THEORETICAL MATRIX}

It is useful to determine when collaboration is more advantageous than other mechanisms. In other words, when does collaborative governance contribute to policy design and implementation, and when is it just a burden that complicates or diverts the process with discussions that are time consuming and expensive in terms of money and other resources (Booher 2004; Rummery 2006)?

Given that collaborative arrangements are often regarded as a policy tool (Ansell, Sørensen, and Torfing 2017) for problem solving, they influence political capacities in policymaking for two reasons. First, they involve the allocation of power and resources (Colebatch, Hoppe, and Noordegraaf 2010). Second, they involve various political actors who must decide when and if to implement them.

Ansell (2012) claims that collaborative governance is an alternative strategy to two other well-known strategies in democracies: the managerial strategy and the adversarial strategy. While the first is based on the ability of experts to contribute to decision-making processes, the second emphasizes the competitive aspects of democracies, and the legal strategies of control and supervision (Ansell 2012: 503). Both, Ansell claims, distance the decision-making process from the political process and therefore from the public (Ansell 2012: 503). Collaborative governance is supposed to bring politics back into the administrative process and to give life to negotiations that are lacking in the legal process. Emerson, Nabatchi, and Balogh (2012) claim that collaborative governance can exist only when there is no other option.

However, the unanswered question is when does this mechanism have an advantage over others? In other words, when is collaborative governance the best strategy for the best decision-making process?

In 1959 Thompson and Tuden offered a typology of decision strategies in organizations (p. 197). Continuing Simon's (1947) analysis that distinguished between value and factual elements in decisions, they formulated a $2 \times 2$ matrix, which resulted in four situations for the various kinds of decision strategies. These strategies, illustrated and adapted to collaborative governance in Table 15.1, are a result of the extent of agreement or disagreement about the facts and value elements, as Simon (1947) called them, or about the belief in causation 
Table 15.1 Decision-making strategies and their implications for collaborative governance

\begin{tabular}{lll}
\hline & Agreement on facts & Disagreement on facts \\
\hline Agreement on & Traditional Government - Traditional & Knowledge-Oriented Collaborative \\
values & centralized government in which & Governance - Stakeholders engage in \\
& collaborative governance is not needed & learning and knowledge production \\
Disagreement on & Value-Oriented Collaborative & Government in Search of Decisions - \\
Values & Governance - Stakeholders engage in & Inspiration/risk taking initiatives \\
& deliberating on values and priorities & No place for collaborative governance \\
\hline
\end{tabular}

and the preference for the outcomes, as Thompson and Tuden (1959) called it. Thus, the first axis presents the agreement or disagreement about the knowledge needed to make a decision. For example, experts agree that radiation is harmful, but they do not agree about the acceptable level of radiation from antennas near schools and its impact on children in and around the school. The second axis presents the agreement or disagreement about the values at the heart of the policy. For example, there is no value agreement about the need for gun control.

Relying on the evolution of the matrix and its relevance for administration and the division of labor (Dery 1996), the first type of decision is a classic government decision. In this situation, there is no disagreement about the values at the heart of the policy or knowledge about how to execute it. In other words, the government knows what to do and how to do it. The second type of decision is the experimental decision. In this situation, there is disagreement about how to decide on or implement the policy due to insufficient knowledge. Learning is the best strategy for this situation. The third type of decision is a value-related decision. In this situation, there is disagreement about the values at the heart of the policy but not on how to implement the policy once it is agreed upon. Utilizing political tools such as negotiations will help in these situations. In the fourth type of decision there is a lack of knowledge needed to determine the policy and disagreement about the policy's core values. This situation makes it extremely difficult to even begin thinking about a decision, let alone implementing a policy.

Before applying this typology to collaborative governance, it is important to note three points. First, there is no dichotomous division between values and facts; applying the matrix to different decisions refers to the proximity to the facts or the value elements (Dery 1996). Second, each decision about various issues can be associated with a different label at different times depending on its content, context and developmental stage. Third, using this typology does not suggest the best strategy for a policy issue but rather provides a diagnostic tool for the decision maker to identify a more beneficial administrative action. 
Thinking of collaborative governance in terms of a decision-making strategy helps us answer the question of when it is beneficial for government to engage in it. We propose that two situations are considered worth the time and effort involved in collaborative governance, and two are not. The difference between the two is related to the degree of conflict involved.

\section{The Israeli Case: Exploring Some Examples Via the Collaborative Governance Value Matrix}

We can use the case of Israel to explore the collaborative governance matrix.

\section{Cell 1: traditional government}

When there is agreement on values and facts, the government can decide what it should do and how to do it. We argue that in this case there is no need to engage in collaborative governance and that traditional government is the best strategy for decision-making. For example, when a government needs to issue drivers' licenses, it knows who should have a driver's license and how to issue them. In different situations, it might consider contracting out the driving tests and thus change its decision strategy, but at this point it does not need to collaborate with other actors to decide differently.

In the same manner, it is accepted that a decision about a national immunization program is in the hands of the government and it knows how to do it. Even when considering vaccines outside of these norms, it is still accepted that the best decision-making strategy is a managerial one. For example, on July 29, 2013 the Israeli Ministry of Health initiated an immunization program to provide the population with a booster shot against polio after traces of the virus were found in several areas around the country. Following consultations with international organizations, the ministry launched a special campaign called 'Two Drops' for another round of vaccinations (Even 2013a, 2013b; Ministry of Health 2013a, 2013b, 2013c, n.d.). After six months, the ministry announced that the campaign had achieved its goal when one million children had received the additional vaccine. Before returning to the regular vaccination program, the ministry underscored that the threat was real and due to the special campaign, no child was infected (Ministry of Health n.d.).

This story is interesting because it could have ended completely differently. Many questioned the ministry's professionalism and professional legitimacy, even though it had consulted with experts inside and outside the country (Ilan website n.d.; Matia 2013; Ministry of Health 2013b; Niv 2013). Furthermore, many called for opening the process up to different voices, because there were those who thought the entire campaign was unnecessary (Gal 2013; Gershoni and Bahrah 2013; Globes Service 2013; Magnazi 2013). 
Despite the pressure to involve other people in the decision-making process, in this case, the ministry chose to consult with others but made the final decision on its own without creating a formal mechanism. Hence, in this case, the government decided it knew what to do and how to do it. In other words, there was an agreement on both the values and the facts. This is an example of the advantages of the managerial approach. In this instance, collaborative governance would not have increased the ability to implement the policy or its legitimacy, and certainly would not have increased public value.

\section{Cell 2: knowledge-oriented collaborative governance}

In this cell stakeholders engage in learning. Here there is agreement about the values, but there is disagreement or a lack of knowledge about the facts. Hence, the government agrees about what should be achieved but does not agree on how to do it. In this cell, we argue, collaborative governance can help promote public value.

Collaborative governance as a mechanism that brings together various stakeholders can help share knowledge from various sources and places (Van Buuren 2009). This kind of learning requires collaboration, because it is deliberative. Therefore, it flourishes with the involvement of a variety of actors, which helps legitimize the resulting policy and its implementation.

For example, for many years, organizations from different sectors have initiated and operated extra-curricular programs in the educational system. The Ministry of Education regulated this process (Director General's Memorandum 2.1-12). However, many principals felt that they did not have enough knowledge to choose among the programs. Moreover, the ministry felt it did not have enough knowledge to formulate the needed regulations.

In November 2012, the ministry established the 'Unit for Cross-Sectoral Programs and Partnerships.' The initial goal was to take charge of the numerous extra-curricular programs being offered to the schools. Later, it was used to share knowledge about these programs and innovations (Director General's Memorandum 9.12-1). The unit assembled round tables for creating a computerized database of the extra-curricular programs, building a model of how to engage with the programs and formulating a written agreement about the essence of the collaborative cooperation. What began as an unwieldy situation resulted in a collaboration that involved policymaking and implementation (Director General's Memorandum 9.12-1). One of the specific examples of this process is the round table on programs for LGBT (lesbian, gay, bisexual and transgender) youngsters. The collaboration helped build agreed-upon programs for parents, teachers and students and establish a budgetary allocation from the ministry. Today external organizations want to take part in this process and take the feedback they receive seriously. The ministry, in return, 
includes organizations from different sectors in the design and implementation of the database (interview Michal Oz-Ari, April 2, 2017²).

After trying to take control of an issue it did not have the knowledge to solve, collaboration helped the ministry learn how to design a better policy and promote public education. Moreover, the deliberative process adopted helped the implementers learn how to execute the policy. Eventually, the process was reciprocal in nature and most importantly helped the school principals learn about the programs available and obtain feedback about their value.

\section{Cell 3: value-oriented collaborative governance (VCG)}

In this cell stakeholders help clarify and determine value preferences. Here there is disagreement about the values and agreement about the facts. Hence, the government knows how to execute a policy but does not agree about which value is most important. We argue that in this situation collaborative governance can be helpful.

The collaborative governance mechanism-based on the desire for consensus - can help in such cases to create a political process of negotiation and compromise. The participation of various actors and the ability to reach an agreement may help government achieve more legitimacy than otherwise. The dispute over values can be seen as a dispute over competing values or a disagreement over priorities.

An example of competing values is the dispute on society's ethos. While there is a notion that every society has a set of common beliefs and core principles that are important to it, their normative form is in dispute. One initiative to deal with this sensitive issue in Israel has come from a group of philanthropists and is called 'Living Together.' Their intention is to create a common ethos for Israeli society based on shared responsibility and solidarity. This ethos encourages the creation of a common society, celebrates the differences of each group in society, and rejects violence and racism (interview Miki Nevo, January 28, $2017^{3}$ ). Their initiative has brought together several actors, all with the same goal - to resolve disagreements about values.

Thus, when there is disagreement on policy values or when government tries to implement goals that create disputes over values, collaborative governance is a mechanism that helps government gain legitimacy for its proposed policy and change value preferences.

\section{Cell 4: government in search of decisions}

In this cell, the government is in search of decisions, because there is no agreement about values or facts. Thus, when the government does not agree on what to do and does not know how to do it, as illustrated in this cell, we argue that it should not engage in collaborative governance as a strategy for decision making. 
There are two different situations that exemplify this cell. The first is when there are issues that are best left untouched because of their extremely divisive nature. The second is when the issue is quite new. In both cases there is a need for inspiration or courage in decision making. Therefore such decisions should not be made through collaborative governance.

Immigration in the age of globalization is an example of the first situation in this cell. In this case there is disagreement about both the values and facts. Israel was established as the homeland of the Jewish people. To maintain this goal, it has limited the immigration of non-Jews. However, since 1990 questions about this goal have been raised, especially with regard to those who have sought entry into the country for work or as refugees. Therefore, the value of Israel as a Jewish state has been weighed against the value of opening its gates. Regarding the facts, there are disagreements about the appropriate methods for dealing with illegal immigrants and refugees. Although some steps have been taken with regard to this issue, a clear decision on the subject is very complicated and problematic in the Israeli context (Dror 2011; Efraim 2011; Knesset committee on foreign workers 2006; Yaron et al. 2013 in Slonim-Nevo and Lavie-Ajayi 2017). Thompson and Tuden (1959) describe this situation as an 'anomic structure.'

The second example is a situation where the subject is so new that government needs to decide by itself about the course of action it wants to pursue based on both establishing new value preferences and gathering new knowledge. For example, there are challenges to the basic notion of the value of work (Gorz 1999; Van Parijs 2004) and explorations of alternative contributions to society. These ideas have led to the international movement 'Universal Social Income, UBI' (Van Parijs 2004) as one illustration of the subject.

While some countries are experimenting with the basic income idea (AFP 2016; Henley 2017; Hildestaim 2016), in Israel there is a lack of agreement or knowledge about the issue (Ahitov 2016). This idea, which requires new thinking about the state's economy and the immediate connection between a salary and work, is not one that collaborative governance could shed light on or increase its legitimacy. This is a case that needs a visionary, someone who is willing to take a risk.

Both examples require more time to mature. Therefore, the demands of collaborative governance, including the process of deciding on a policy and implementing it together in a reciprocal manner, make this choice an inappropriate one. In these cases, collaborative governance can be a burden and even hamper the policy and the connection between the actors altogether. In this situation, it will not have the ability to design a policy or legitimize it, and certainly will not help increase public value. 


\section{THE DECISION-MAKING STRATEGIES MATRIX AND THE DIFFERENT MODES OF COLLABORATIVE ARRANGEMENTS IN PUBLIC SERVICE DELIVERY}

As suggested above, the definition of collaborative governance that we embrace is more specific than the general notion of collaboration. Several elements are important. The first is that we focus on the central place of government. The second is that collaborative arrangements include different stakeholders from different sectors. The third is that it is a formal process, and the fourth is that it is a consensus-oriented and deliberative process. Collaborative governance arrangements aim at the design and implementation of public policy and/or the management of an asset or a program. Therefore, they include the focus of this book - public service delivery arrangements - but go further to more macro level policies such as the design of broad environmental policies on the one hand and to more specific programs on the other.

To demonstrate the relevance of our matrix to the six public service delivery arrangements, we must first match them with the definition of collaborative governance as we use it. Table 15.2 refers to the three main elements elaborated above: the centrality of the government in the collaboration, the diversity of stakeholders and sectors that are part of the arrangements, and the level of deliberation and consensus building that is included in the process of this arrangement. As the table illustrates, three of these arrangements do not accord with the definition of collaborative governance. Both consulting and contracting out are two arrangements in which the government is the leading actor but at the same time the role of the other partners in the process is minor and limited to giving advice or following the government's lead. Therefore, the elements of collaboration that include deliberation and/or consensus building are almost non-existent. The third arrangement - certification-does not require the government to play a central role in the collaboration and therefore does not fit the character of collaborative governance as defined above.

The three other kinds of collaborative service arrangements - commissioning, co-management and co-production - have a better match with our definition of collaborative governance. In these three arrangements there is a high level of collaboration between various partners. In 'commissioning' the collaboration with other NGOs and private suppliers is mostly at the design stage, but not only (Rees, Miller and Buckingham 2017; Williams et al. 2012). In 'co-management' the collaboration is between the different sectors in designing and implementing the policy (Berkes 2009). Finally, in 'co-production' it is mostly with those who are utilizing the services (Strokosch and Osborne 2016). In all of these arrangements the government is still a central actor. 
Table 15.2 The six collaborative service arrangements, the centrality of the state, the actors and deliberation

\begin{tabular}{llll}
\hline & $\begin{array}{l}\text { The centrality of the } \\
\text { state }\end{array}$ & $\begin{array}{l}\text { The diversity of the } \\
\text { partners-stakeholders/ } \\
\text { sectors }\end{array}$ & $\begin{array}{l}\text { The deliberation and } \\
\text { consensus-oriented } \\
\text { process }\end{array}$ \\
\hline Consulting & +++ & + & + \\
Contracting & +++ & + & + \\
Commissioning & +++ & +++ & ++ \\
Co-management & ++ & +++ & +++ \\
Co-production & ++ & ++ & ++ \\
Certification & + & +++ & ++ \\
\hline
\end{tabular}

Notes: + low/++medium/+++high.

Utilizing the matrix, we can also investigate whether the three arrangements occur more due to the need to demonstrate that all of the actors agree on the values and create legitimacy for the activities or whether they result from the partners' need to share information and knowledge in order to create better services. We assume that the second reason is the more likely one.

The importance of knowledge and information are particularly relevant due to the specific orientation of service delivery arrangements. While the value component is part of all of the actions of public policy and/or public organizations, in the context of public services, issues of scarcity and the need for relevant knowledge are critical. Given that professionals may have common core values (Sabatier 1998), lack of knowledge is often the key issue (Berkes 2009). Moreover, processes such as decentralization and privatization have fragmented public services and scattered the knowledge about how to supply services among different actors and the ability of government to bring together this knowledge (Williams et al. 2012). Moreover, the days of a one size fits all policy that requires building agreements around one service have passed. Sociological trends such as individualism and post-Fordism have created greater and more accurate demands from citizens regarding the quality of public services. Most prominent is the demand from service recipients that services be tailored to their specific needs. Therefore, as Figure 15.1 illustrates, we place these three arrangements closer to the end of the spectrum aimed at decision-making strategies that are more knowledge-oriented. 


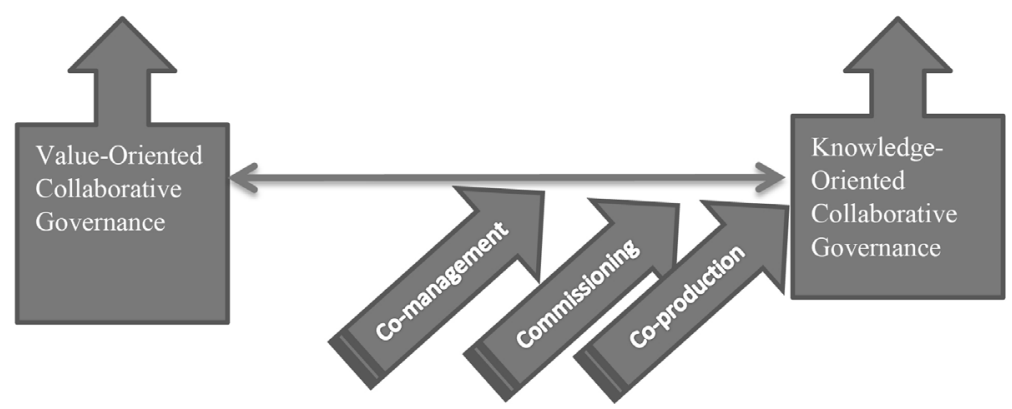

Figure 15.1 Types of collaboration in service delivery and the value-oriented versus knowledge-oriented range of decision making

\section{CONCLUSIONS AND PRACTICAL IMPLICATIONS FOR COLLABORATION}

Collaborative governance arrangements are confusing. While they are often touted as a worthier tool in a world of multiple actors and a fluid and dynamic public policy arena, they are also costly, difficult to manage and even sometimes risky for democracy.

Moreover, in an era when there is little trust in policymakers as well as the political system as a whole, and the political system suffers from a lack of legitimacy, we hope that our theoretical conceptualization can contribute to strengthening political capabilities. Embracing a more nuanced awareness of the varied nature of decision-making situations can help political actors choose the best policy tools. In this chapter, we tried to cope with these challenges by asking two questions - when is it worthwhile to embrace collaborative governance arrangements, and when is it not?

For this purpose, we used Thompson and Tuden's (1959) theoretical matrix to decide whether it is worthwhile to engage in collaborative governance efforts and of what kind. We then explored this matrix with some preliminary examples from the Israeli case and reflected on its relevance to the specification of service delivery arrangements.

The collaborative governance matrix can help us determine when to create these arrangements, who should participate, what is meant to be achieved and whether or not they are the best choice of method. 
We claim that the two cells in the matrix that are beneficial for embracing collaborative governance highlight the different situations for capacity and legitimacy that promote public value. Furthermore, they suggest the elements that should be emphasized when recruiting the various stakeholders. Thus, when there is a need to create more value preference consensus such as in the value-oriented collaborative governance cell, the emphasis should be on recruiting diverse representative stakeholders. In contrast, in the case of knowledge-oriented collaborative governance where the need is to create knowledge, the recruitment should be based on the information held by the various stakeholders. In the specific context of service delivery arrangements, the issue seems to be one related to a lack of knowledge rather than a conflict of values. When there is disagreement on both elements, there is a need to create an inspirational process that might ultimately result in implementation by the government.

Finally, these arguments exemplify how collaborative governance is but another tool that governments can utilize in making decisions. Hence, although collaborative governance is part of the third wave of government reforms, as in previous reforms the goal is not to replace governmental arrangements altogether but to adopt more diverse mechanisms according to the specific situation. This chapter seeks to contribute to the issues that need to be recognized when considering adopting collaborative governance mechanisms. Ultimately, our goal is to help answer the question: Given the diagnosed situation, how can we use these mechanisms in a more beneficial way to promote public values? We explored some examples from the Israeli context at a specific point in time. Future studies could use more detailed experimental case studies from different countries. Researchers could also investigate different kinds of service arrangements such as commission, co-management and co-production using the typologies and ideas suggested here to enrich our exploration of this question empirically and theoretically.

\section{NOTES}

1. This work was supported by The Center for Social Justice and Democracy in Memory of Yakov Chazan at the Van Leer Jerusalem Institute. Part of this chapter is based on a chapter that is supposed to be published in a book (in Hebrew) concerning collaborative governance in Israel. We would like to thank Professor Itzhak Galnoor, the Academic Director of the Center, for his illuminating remarks. We are also grateful to our research group at the center, especially Nomika Zion and Dr Varda Shiffer and the editors of the current book for their important remarks that help improved this chapter.

2. Interview with the supervisor of external programs and inter-sectoral partnership at the pedagogical administration, Ministry of Education, Michal Oz-Ari, April 2, 2017.

3. Interview with the director of 'Living Together,' Miki Nevo, January 28, 2017. 